International Journal of Current Advanced Research

ISSN: O: 2319-6475, ISSN: P: 2319 - 6505, Impact Factor: SJIF: 5.995

Available Online at www.journalijcar.org

Volume 6; Issue 3; March 2017; Page No. 2789-2792

DOI: http://dx.doi.org/10.24327/ijcar.2017.2792.0105

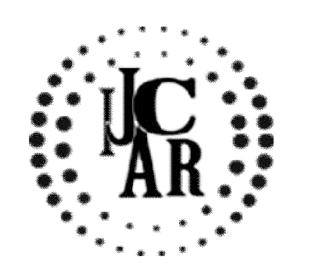

Research Article

\title{
CONSUMPTION OF CARBONATED BEVERAGES AMONG DENTAL STUDENTS
}

\section{*Pawan Kumar Earasi and Dhanraj}

Saveetha Dental College and Hospitals, Poonamallee High Road, Chennai-600077

\section{A R T I C L E I N F O}

\section{Article History:}

Received $18^{\text {th }}$ December, 2016

Received in revised form $16^{\text {th }}$ January, 2017

Accepted $26^{\text {th }}$ February, 2017

Published online $28^{\text {th }}$ March, 2017

\section{Key words:}

Perturbed differential equations, delay, collocation method, Finite Element Method. \begin{abstract}
A B S T R A C T
Aim: To evaluate knowledge, attitude and practices of soft drink consumption and their dental health between the age groups of 18-24.

Materials and Methods: Formulation and distribution of a survey/ questionnaire was conducted among the students studying Bachelor of Dental Surgery (BDS) at Saveetha Dental College.
\end{abstract}

\section{Results}

- $\quad$ Approximately $84 \%$ of the students preferred carbonated drinks over fruit juices and other beverages; $48 \%$ cola, $36 \%$ pepsi, remaining preferred fruit juice and other beverages. (Graph 1)

- $64 \%$ of the students consumed beverages twice per day; $49 \%$ consumed two bottles per day and $37 \%$ consume three bottles per day. $17 \%$-consumed beverages once per day, $14 \%$ consumed thrice per day and $15 \%$ consumed more than three times per day \& more than three bottles per day. (Graph 2)

- Roughly $75 \%$ believed there is an increase in consumption over time where as $25 \%$ believed it decreased with time. (Graph 3)

- $\quad 57 \%$ of students were aware of the ill-effects of consuming carbonated beverages, but $43 \%$ were not aware of the calories intake by consumption of a glass of cola and sugar free carbonated beverages.

- $\quad 41 \%$ did not experience ill-effects where as about 59\% had been effected. (Graph 4)

- $73 \%$ of students did not feel any changes discomfort or change in their oral environment after consuming the soft drink but $27 \%$ felt discomfort after few minutes of consumption. (Graph 5)

- $\quad$ Approximately $63 \%$ of students consumed soft drink by bottle, $31 \%$ using a glass and $6 \%$ by straw. (Graph 6 )

\section{Conclusion}

- With the gathered results, I came to a conclusion that most of the students preferred to drink cola over other drinks such as pepsi, fruit juice, etc.

- A factor that was noted was that they were aware of the ill-effects of carbonated beverages, still their consumption increased day by day, but resulted in not experiencing any ill-effects after intake.

- Most students who participated were not aware of the sugar-free carbonated beverages and the amount of calories that is taken in by one glass or can of carbonated beverage.

- $\quad$ Several students showed early signs of erosion and dental caries; felt discomfort for minutes due to the fact that the enamel is eroded or in the process of becoming eroded.

Copyright $@ 2017$ Pawan Kumar Earasi and Dhanraj. This is an open access article distributed under the Creative Commons Attribution License, which permits unrestricted use, distribution, and reproduction in any medium, provided the original work is properly cited.

\section{INTRODUCTION}

In the modern society many individuals are drawn into the consumption of soft drinks for their own personal reasons. Carbonated beverages are referred to by various names in different counties such as soft drink, coke, fizzy drink, fizzy

\section{*Corresponding author: Pawan Kumar Earasi}

Saveetha Dental College and Hospitals, Poonamallee High Road, Chennai-600077 juice, cool drink, cold drink, lolly water, pop, seltzer, tonic, soda and much more. These carbonated beverages, soft drinks, are the second most consumed beverages to water. People consume these beverages everyday without the mindset of the negative impacts, which affects both their general and dental health. Recent publications in the United States of America have released stats proving Americans consume around 57 gallons of soft drinks per person every year. As individuals are not aware of the ill effects of consumption of these beverages, the cycle never ends without 
the truth of what happens in the body with each sip. [1] [4] When soft drinks, soda, is swallowed, the pancreas is alerted about thecontemporarysubstance in the body and the rapid process of creating insulin is initiated in the response to the sugar. Insulin is a hormone in the body, which moves the sugar found in food and drinks in the bloodstream, where cells are then capable to transform the sugar for energy. In twenty minutes, the blood sugar levels are raised where the liver responds to the insulin by turning the sugar into fat for storage. Within the forty-five minutes of consumption of the a simple 20 ounce bottle of soda $(591 \mathrm{ml}$; roughly the average size of a soda bottle), caffeine, which is an ingredient that adds the flavor in carbonated beverages, is absorbed as this results in the dilation of the pupils and increased blood pressure. The human body produces more dopamine, functions as a neurotransmitter in the brain, which simulates the pleasure centers of the brain. The cycle is repeated within as hour when people experience their blood sugar levels crashing and they reach out for a second soda.[1] [3] [5] Although the connection between carbonated beverages and obesity epidemic is intertwined, researchers from Harvard University have determined with each additional soda that is consumed, increases the threat of obesity by 1.6 times. The results show that after closely following forty thousand men for two decades, those who consumed the sugary drink each day had a twenty percent increase of having a heart attack. [2] Increased risk of metabolic syndrome, which leads to heart disease and diabetes, is associated with the high fructose corn syrup used as a cheap replacement for cane sugar. [4]

Beverage companies in countries such as the United States, spend approximately 3.2 billion dollars in marketing itself each year to tempt citizens to purchase soda even if it's with their pizza or a case of cans for a party. As more people consume soda on a regular basis, there is an eighty percent increased threat of developing type 2 diabetes. They may face numerous complications such as kidney problems, asthma, reproductive issues, osteoporosis, and even bad teeth with dissolved tooth enamel. [1] [5]Several studies conducted by numerous research teams in different parts of the globe, have indicated that there is a relationship between the cumulative caries scores, regularity of mealtime and between-meal with carbonate beverage intake. The wear down of enamel and dentine occurs though attrition, process of reducing the strength or effectiveness of something. Enamel and dentine are exceptionally sensitive to erosion, and this chemical wear process may exploit in synergism with physical wear processes, particularly abrasion. [3] The significance of erosion of tooth wear has been acknowledged over a span of numerous decades with both intrinsic and extrinsic acids.

However studies imply that immature enamel is porous and can be easily dissolved by acids until the intraoral maturation of the surface enamel has occurred. As the immature enamel is submerged in salivary ions, it becomes progressively harder, fairly resistant to acid attack and less penetrable. [2] Although adults do consume carbonated beverages, there is a greater percentage that is consumed by young children. Since the enamel maturation takes time over several years, young child are at greater risk of dental caries. [1] Erosion of the tooth usually occurs due to two reasons which are the dissolution of the enamel and when the $\mathrm{pH}$ level has fallen below the critical pH, 5.5. Erosion can be induced as a product of many acidic drinks such as fruit juices, carbonated soft drinks. [5] Through countless number of epidemiological studies, it is confirmed that there is a relation between erosion and the acidic drink intake. More intakes of carbonated drinks will equal to higher chances of dental erosion. As expressed, when an individual is affected by dental erosion, the oral $\mathrm{pH}$ levels become lower for more time and their carbonated beverage drinking habits play a significant role and have tremendous impact on both dental and general health. [1] [3]

\section{MATERIALS AND METHODS}

The study to evaluate knowledge, attitude and practices of soft drink consumption and their dental health was carried out among the students who attend Saveetha Dental College \& Hospitals and are enrolled in the Bachelor of Dental Surgery (BDS) program. The targeted population for the study was 40 dental students within the age groups of 18-24. In this study, there was a formulation and distribution of a survey/ questionnaire, which was conducted among the students. The questionnaire consisted of eleven general questions to test not only their experiences and practices but also their awareness of the issue.

\section{RESULTS}

By this study, I came to know that approximately $84 \%$ of the students preferred carbonated drinks over fruit juices and other beverages. $48 \%$ preferred cola, 36\% preferred chose pepsi, remaining preferred fruit juice and other beverages (Graph 1). Approximately, 64\% of the students consumed beverages twice per day, $49 \%$ of the subjects consumed two bottles per day and $37 \%$ consume three bottles per day. $17 \%$ consumed beverages once per day, $14 \%$ consumed thrice per day and $5 \%$ consumed more than three times per day \& more than three bottles per day (Graph 2). Roughly $75 \%$ believed that there is an increase in consumption over time where as $25 \%$ believed it decreased with time (Graph 3). Approximately, $57 \%$ of students were aware of the ill-effects of consuming carbonated beverages, but $43 \%$ were not aware of the calories intake by consumption of a glass of cola and sugar free carbonated beverages. About, 41\% did not experience ill-effects where as about $59 \%$ had been effected (Graph 4). $73 \%$ of the dental students did not feel any changes discomfort or change in their oral environment after consuming the soft drink but many of them, around $27 \%$ felt discomfort after few minutes of consumption (Graph 5).63\% of students consumed soft drink by bottle, $31 \%$ using a glass and $6 \%$ by straw (Graph 6 ).

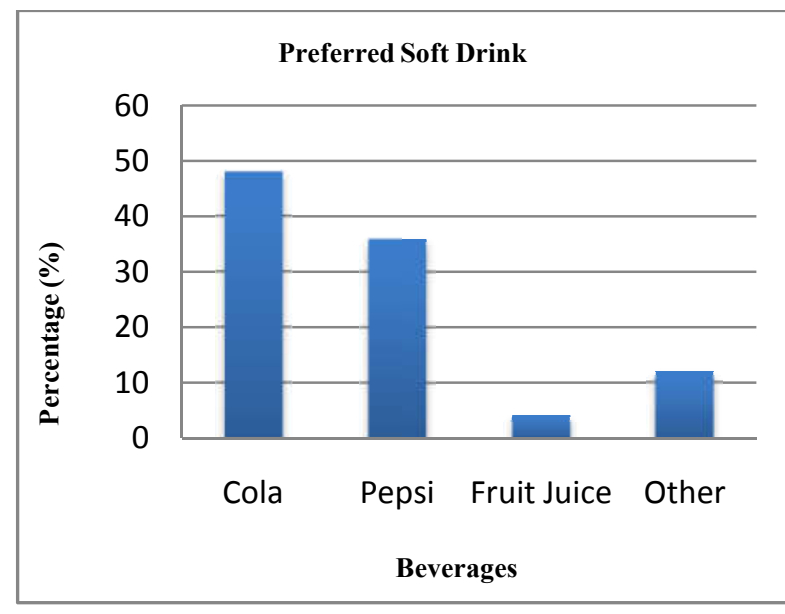

Graph 1 The most preferred soft drink 


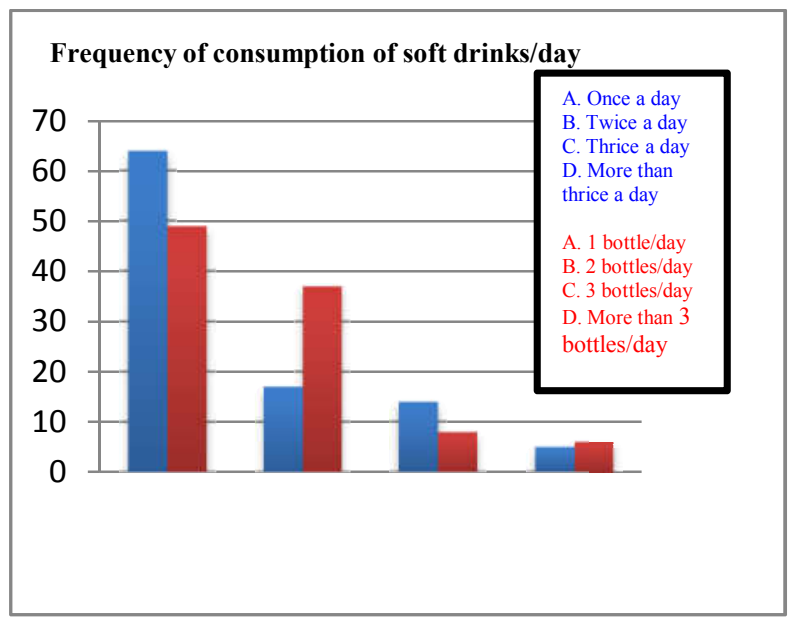

Graph 2 The frequency of consumption of soft drinks per day

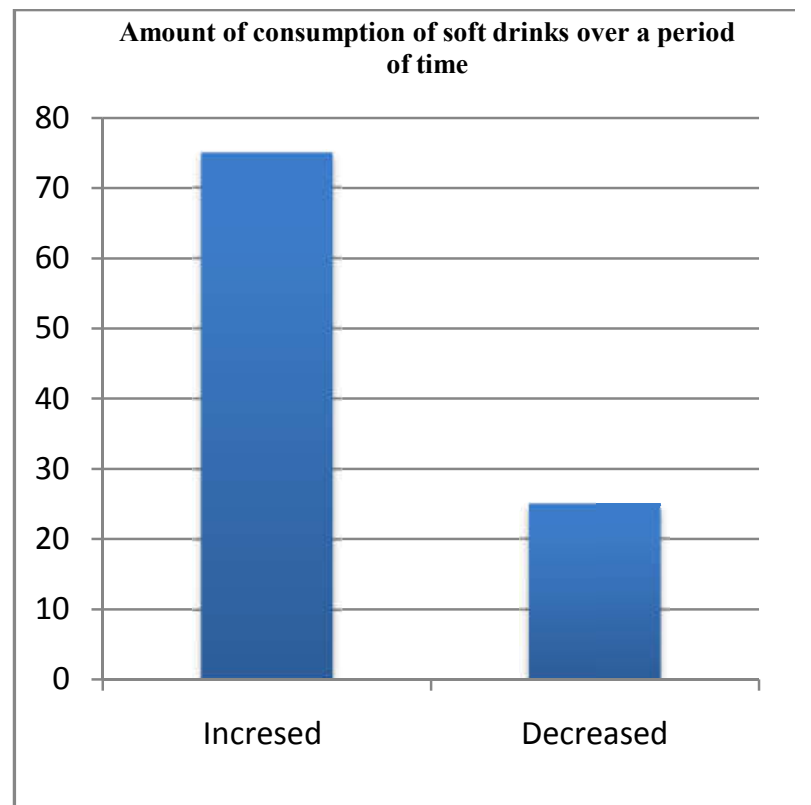

Graph 3 The amount of consumption of soft drinks over a period of time

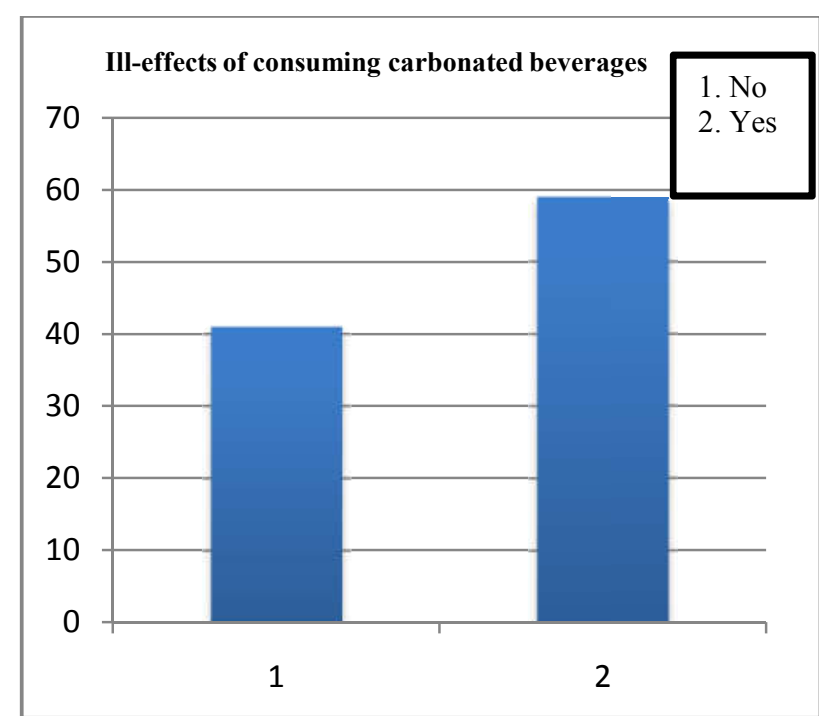

Graph 4 The ill effects of consuming carbonated beverages

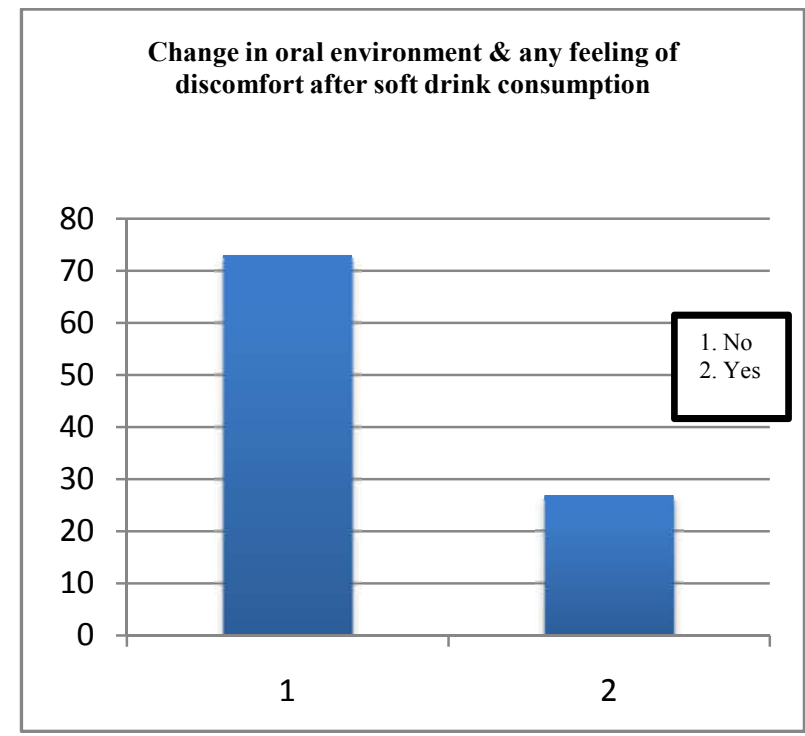

Graph 5 Any change in oral environment and any feeling of discomfort after soft drink consumption

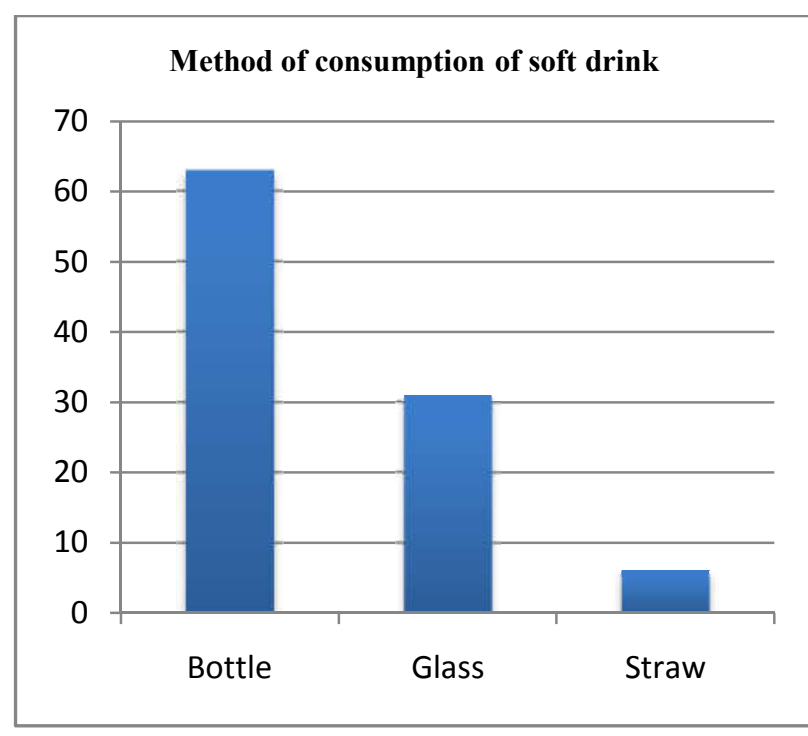

Graph 6 The method of consumption of soft drink

\section{DISCUSSION}

There is the ideal environment for development of dental caries, which lays between the high acidic $\mathrm{pH}$ of soft drinks and the sugar contained in the beverage. Carbonated beverages and fruit juices are known to be acidic which are also known to contribute to the erosion in the dental enamel. Every beverage consumed cause an alteration in the salivary $\mathrm{pH}$ level as it differs in many degrees. [5] Erosion can be caused when soft drinks which are carbonated is taken into the body which has low $\mathrm{pH}$, large amounts of sugar and various additives that hook an individual to be addictive to the certain product. Intake of carbonated beverages during meal times is less injurious than consumed alone. [1] Drinking the acidic liquid at once is less harmful than continuously sipping. Beverages such as cola carry out a property to be retained on the tooth surface, which is difficult to eliminate by saliva, causing an increase of cariogenicity. [3] Although many reasons have been stated for being the vital factor in the development of dental erosion, acidity in drinks is considered number one due to the availability of the hydrogen ions, which interacts with the enamel. The results gathered can 
come down to few solutions and tips. As mentions before, the duration of contact between the teeth and the acidic beverage is a significant factor contributing to erosion. Swallowing at once will minimize the risk while prolonged sipping will increase the risk. Many ways can be adapted to limit the contact time such as using a straw. After the consumption of soft drinks, rinsing with water or drinking a glass of milk immediately will help with the clearance of acidity in the mouth and will contribute to bringing the oral $\mathrm{pH}$ level to neutral. [2] The misuse of acidic medication, including vitamin $\mathrm{C}$ can have an effect. Chewing or simply using such pills as lozenges increases erosion factor, which is why individuals are told to swallow their prescribed medication. As people intake carbonated beverages, they are aware of the typical drink that contains carbonated water, a sweetener and a natural or artificial flavoring. Some may be mindful of phosphoric and citric acid that is contained but other organic acids such as malic and tartaric may also be present. The presence of the acids in beverages are essential due to their ability for calcium ions to bond to a central atom at two or more points even at a high $\mathrm{pH}$ levels. The study acclaimed of dental erosion in great matter, and the frequent intake of the erosive carbonated beverages with low $\mathrm{pH}$ values was the factor, which identified for the development of dental erosion.[1] [5] [3]

\section{CONCLUSION}

With the gathered results, I came to a conclusion that most of the students preferred to drink cola over other drinks such as pepsi, fruit juice, etc. A factor that was noted was that the test subjects were aware of the ill-affects of carbonated beverages, still their consumption increased day by day due to addictiveness, but resulted in not experiencing any ill-effects after intake. Most students who participated were not aware of the sugar-free carbonated beverages and the amount of calories that is taken in by one glass or can of carbonated beverage. Several students showed early signs of erosion and dental caries and felt discomfort for minutes due to the fact that the enamel is eroded or in the process of becoming eroded.

\section{References}

1. Vartanian, Lenny R., Marlene B. Schwartz, and Kelly D. Brownell. "Effects of Soft Drink Consumption on Nutrition and Health: A Systematic Review and MetaAnalysis." American Journal of Public Health. (C) American Journal of Public Health 2007, Apr. 2007. Web. 15 Feb. 2017. (info)

2. Sturgeon, Jamie. "Soft Drinks an Increasingly Hard Sell to Canadian Consumers." Global News. N.p., 29 Oct. 2014. Web. 15 Feb. 2017.

3. Sanger-Katz, Margot. "The Decline of 'Big Soda'." The New York Times. The New York Times, 02 Oct. 2015. Web. 15 Feb. 2017.

4. John, Dr. Tina M. St. "Side Effects of Carbonated Drinks." LIVESTRONG.COM. Leaf Group, 30 June 2015. Web. 15 Feb. 2017.

5. "Sugary Drinks and Obesity Fact Sheet." The Nutrition Source. N.p., 26 May 2015. Web. 15 Feb. 2017.

\section{How to cite this article:}

Pawan Kumar Earasi and Dhanraj (2017) ' Consumption of carbonated beverages among dental students', International Journal of Current Advanced Research, 06(03), pp. 2789-2792.

DOI: http://dx.doi.org/10.24327/ijcar.2017.2792.0105 